\title{
Los oficios de la maternidad \\ Una mirada desde la antropología médica
}

\author{
Soledad González Montes
}

ROSA MARÍA OSORIO CARRANZA, 2001

\section{Entender $y$ atender la enfermedad.}

\section{Los saberes maternos frente a los}

padecimientos infantiles

INI, CIESAS, Conaculta-INAH, México.

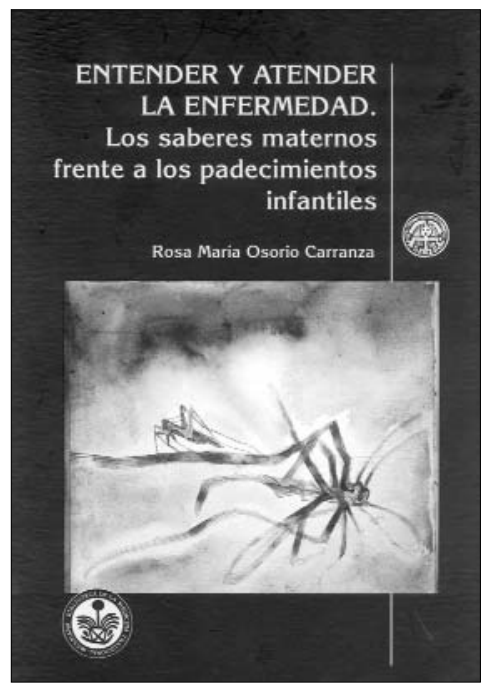

Q

ue las mujeres cuiden a sus hijos y los atiendan cuando están enfermos es algo que parece "natural", es decir, que se considera como parte inherente a la función materna, prácticamente un "instinto materno". "Desnaturalizar" un fenómeno es el primer paso indispensable para convertirlo en objeto de estudio antropológico. Éste, justamente, es uno de los objetivos del libro de Rosa María Osorio: desnaturalizar el papel de las madres como guardianas de la salud infantil y argumentar que esta función les está social y culturalmente asignada a las mujeres en la división sexual del trabajo. Osorio procede entonces a documentar minuciosamente la complejidad de lo que las mujeres tienen que aprender, practicar y transmitir si desean dar adecuado cumplimiento al mandato social de la maternidad.

El libro recupera "el punto de vista del actor", en este caso las madres,

SOledad GONZÁlez montes: Programa Interdisciplinario de Estudios de la Mujer de El Colegio de México.

Desacatos, núm. 13, invierno 2003, pp. 200-203.

para dar cuenta del papel estratégico que tienen en la atención de la salud familiar, en particular la de los niños pequeños. Con este propósito se describe y analiza en detalle todo lo que involucran los saberes y las prácticas maternas en materia de salud infantil, en el contexto de una pequeña localidad del municipio de Huixquilucan, Estado de México. Allí la mujer/madre es la que detecta los primeros signos de alarma, diagnostica, cuida, identifica la gravedad de cada caso y canaliza al enfermo, aplica los tratamientos, cuida la alimentación y toma medidas de prevención. Se trata de una enorme responsabilidad que exige de la mujer 
las capacidades y conocimientos necesarios para evaluar los síntomas de las enfermedades, los recursos con los que cuenta la familia, las opciones terapéuticas disponibles y los resultados de experiencias previas.

La importancia del papel de las mujeres en materia de salud familiar ya había sido identificada y subrayada por Eduardo Menéndez y Carlos Zolla en sus trabajos sobre autoatención y medicina doméstica, respectivamente.

María Eugenia Módena analiza en su libro Madres, médicos y curanderos (SEP/CIESAS, 1990) la manera en que las madres de una región veracruzana utilizan los diversos recursos terapéuticos a su alcance, provenientes de la medicina tradicional, la medicina institucional e, incluso, de fuentes religiosas. Con estos antecedentes, Rosa María Osorio amplió y profundizó el campo de investigación en torno a la temática, aplicándole nuevas propuestas metodológicas.

¿Qué factores y cómo influyen en la toma de decisiones con respecto a qué hacer frente a la enfermedad de un hijo? Para responder esta pregunta Osorio dio seguimiento a un conjunto de madres a lo largo de un periodo de tiempo, registrando su pensamiento $y$ prácticas en torno a "la carrera del enfermo", un instrumento que resultó ser sumamente eficaz en la recolección sistemática de información sobre la evolución de episodios específicos de enfermedad. Desde la perspectiva emic, la autora analiza las representaciones que las madres tienen sobre la etiología, distribución y frecuencia de los padecimientos más comunes en la infancia. Recupera también los crite- rios, diagnósticos y pronósticos que utilizan, así como las nociones preventivas y terapéuticas que orientan sus decisiones.

Sistematizada esta información, la cantidad de saberes que implica el cuidado de la salud (¡la vida!) de los menores, resulta impactante. Cada caso de enfermedad requiere de las madres una evaluación de los cursos de acción seguidos y los resultados logrados. La eficacia de un tratamiento aplicado es evaluada constantemente, con gran pragmatismo, flexibilidad y rapidez. $\mathrm{Si}$ el tratamiento resulta exitoso se confirma el diagnóstico; si no, se reformula. De modo que cada "carrera curativa" implica un aprendizaje por la vía de la observación, prueba y error.

Uno de los aportes más interesantes del estudio es el análisis del modelo médico que manejan las madres, mostrando que tienen una concepción integral de la salud que vincula las condiciones de vida, las relaciones sociales, las conductas, la alimentación, los estados anímicos, además del contagio y los agentes patógenos, como factores que pueden provocar desequilibrios y enfermedad.

En estos saberes aprendidos, Osorio encuentra multitud de puntos finos. Por ejemplo, el manejo de una noción de "dosis" que toma en cuenta el peso del paciente y su edad para elegir el tipo de tratamiento más eficaz, con la idea de que la dosis debe modificarse según las circunstancias. Otro ejemplo es la noción de "inmunidad adquirida”, que también utilizan las mujeres entrevistadas. Pese a que la mitad de ellas no alcanzó a completar la primaria y vive en condiciones de pobreza, han incorporado estos conceptos de la medicina moderna a sus teorías sobre las etapas del desarrollo de sus hijos y la necesidad de mantener un equilibrio en los cuidados, de no caer en descuidos o exceso de cuidados, por los efectos negativos que puede tener la sobreprotección de los niños.

Más allá de toda duda, la investigación demuestra la existencia de una cultura médica popular compleja, manejada fundamentalmente por las mujeres, que tiene diversos orígenes y fuentes de información, desde las abuelas y otras parientes curanderas hasta los medios de comunicación. Pese a esta multiplicidad de influencias, la conclusión es que los médicos son quienes están teniendo cada vez más peso sobre la cultura de la salud. En este sentido, el análisis de la composición de los botiquines familiares le permitió a Osorio hacer un hallazgo muy interesante: ya a fines de la década de 1980 se tendía a usar más medicinas de patente que caseras o derivadas de la farmacopea tradicional.

Si bien Rosa María Osorio da cuenta de la complejidad y efectividad de la acción femenina en materia de salud infantil, también nos advierte contra una excesiva idealización, porque las madres, como los médicos, no son infalibles y también hay casos de iatrogenia materna. Osorio trata de ubicar el justo aporte de la autoatención y de la función materna en la salud infantil y la conclusión que se desprende de esta investigación es que, considerando que deben actuar en contextos de pobreza y fuertes presiones sobre ellas, las madres estudiadas hicieron 


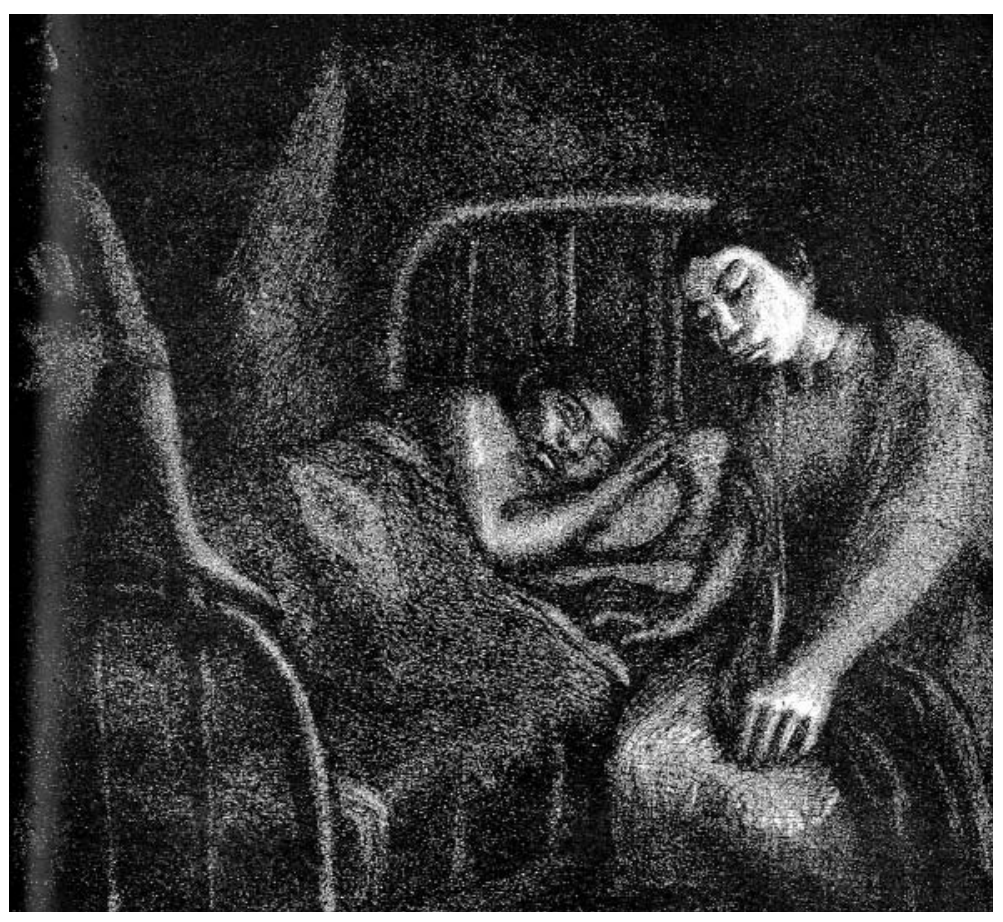

Celia Calderón de la Barca, El paciente, 1950.

un aprovechamiento óptimo de los recursos de los que disponían. Al menos en el contexto del municipio de Huixquilucan, que es más urbano que rural y donde hay un acceso fácil a servicios médicos incluso de segundo y tercer nivel, estas madres tuvieron considerable éxito, a pesar de su baja escolaridad y sus limitaciones económicas.

El esfuerzo que realizan las madres para mantener la salud familiar y el éxito que tienen para que sus hijos "se logren" y sobrevivan al periodo tan vulnerable que es la infancia, choca contra un muro de falta de reconocimiento social que Osorio documenta para el caso de los médicos. Sus entrevistas sacan a relucir la incomprensión y los prejuicios que ellos tienen sobre el quehacer de las madres en materia de salud. No sólo piensan que son "ignorantes" y descuidadas y las culpan por los problemas de salud de sus hijos, sino que también - y sobre todo- les incomoda que tengan criterios propios y no sigan al pie de la letra sus instrucciones. Porque no es raro que una vez que ven que el paciente mejora, las madres decidan discontinuar el tratamiento, en particular si se trata de antibióticos. Osorio explica la racionalidad detrás de esta decisión, que responde a múltiples factores, pero que muchas veces tiene que ver con la idea muy extendida de que la medicina de patente puede tener efectos secundarios y resultar iatrogénica, "que cura de una cosa pero daña otra”.
Este es un libro de una enorme riqueza, por lo que desde luego se presta a múltiples lecturas. Obviamente, realicé la mía desde mis propias preocupaciones y una pregunta que me hice al terminar de leerlo es hasta dónde podemos generalizar los hallazgos de esta investigación. ¿Hasta qué punto el modelo de la madre que toma las decisiones sobre la salud de sus hijos pequeños y a la que se le considera como la "responsable" principal o exclusiva de este papel, es generalizable a otros contextos socioculturales? No es que Osorio nos diga que ha desarrollado un modelo universal, porque en ningún momento ella manifiesta esta pretensión. Más bien se trata de un ejercicio de reflexión que me parece interesante para poner en perspectiva su estudio. La cuestión tiene interés teórico y práctico, porque nos remite inmediatamente al lugar que la joven madre ocupa en la jerarquía de autoridad dentro de la familia, de la que depende quien o quienes toman las decisiones.

En el caso de las madres del municipio de Huixquilucan, si bien Osorio señala que están subordinadas a maridos que con frecuencia las maltratan, está muy claro que ellas son las que toman las decisiones en materia de salud infantil. Pero resulta que en otros contextos las esposas jóvenes no están en la misma posición, como sucede en zonas indígenas donde la pareja reside en familias numerosas. Allí las jóvenes madres tienen una participación mínima o inexistente en las decisiones sobre a quién consultar, porque esta es prerrogativa de sus suegros y su marido. 
Así lo describe, por ejemplo, el estudio de Graciela Freyermuth sobre mortalidad materna en los Altos de Chiapas (Morir en Chenalhó, CIESAS, en prensa). Su investigación prueba que si bien hay representaciones culturales más o menos extendidas en cuanto a la división sexual y generacional del trabajo, también hay maneras muy diferentes y específicas de vivir las relaciones de género y la función materna, según la situación de clase, étnica y cultural. Estas diferencias y especificidades matizan de manera muy importante el grado de autonomía o subordinación de las mujeres, que además suele variar a lo largo de su ciclo de vida, con lo que también van modificándose sus posibilidades de decisión en cuanto a la salud, propia y/o de sus hijos. Este problema no escapa a Osorio, quien señala en las conclusiones la necesidad de futuros estudios de género (y habría que agregar: generacionales) que profundicen en el conocimiento de estas cuestiones.

En este sentido, un tema pendiente es el de los saberes masculinos con respecto a la salud y a sus transformaciones en la última década. Estos saberes serán innecesarios si los varones no son considerados los responsables ni participan en las cuestiones ligadas a la salud, como sin duda ocurre en la actualidad en gran parte de nuestra sociedad urbana. Pero hay contextos en los que esto requiere ser matizado. Por ejemplo, en un pueblo chinanteco, a mediados de la década de 1980 , Carole Browner encontró para su sorpresa y en contra de sus hipótesis iniciales, que los varones sabían bastante más que las mujeres sobre herbolaria en relación con la salud y la reproducción. Es posible que las mujeres hayan fingido ignorancia por razones de género, pero no hay que descartar que en efecto los varones también tuvieran un papel en el cuidado de la salud. Esta cuestión probablemente adquirirá aún más relevancia en el futuro, en la medida en que se afiance la tendencia hacia un mayor involucramiento de los varones en la crianza de sus hijos en las nuevas generaciones, detectada por algunos estudios realizados en contextos urbanos populares.

En las conclusiones a su libro Rosa María Osorio se refiere a las tendencias en los saberes y las prácticas maternas a través del tiempo. Ella encuentra que a fines de la década de 1980 en Huixquilucan las madres jóvenes estaban cada vez más atraídas por el modelo médico hegemónico por su eficacia, aunque todavía la medicina alopática no había desplazado a la tradicional. Una de las preguntas que quedan planteadas es qué está sucediendo con las nuevas generaciones. Aquí la cues- tión parecería ser en qué medida la medicina tradicional y otras formas de medicina alternativa están dando respuesta a necesidades no cubiertas por la biomedicina. Si existen problemas de salud que la biomedicina no logra resolver, indudablemente la gente continuará buscando y recurriendo a otras opciones. En este caso la hegemonía de la biomedicina nunca será completa, como sucede en Estados Unidos y Europa, donde hay un importante mercado para el naturismo y terapias originadas en tradiciones antiguas que se remozan y reciclan.

Finalmente, tendría que ser obligada la lectura de este libro no sólo para los colegas especialistas en antropología médica, sino también para estudiantes de antropología y medicina. Los temas que trata deberían incluirse en la currícula formativa de los médicos, porque los acercaría a la comprensión de las protagonistas principales y estratégicas de la salud familiar y los ayudaría a tener una mejor comunicación con ellas, lo que redundaría en una mayor eficacia en la atención y evolución de sus pacientes. Esto es, en definitiva, lo que quieren decir las organizaciones de mujeres que trabajan por la salud cuando demandan de los prestadores de servicios una verdadera "atención de calidad y con calidez". 